\section{A Interculturalidade Crítica como possibilidade para um diálogo sobre as territorialidades no Brasil $^{1}$ The Critical Interculturality as a possibility for a dialogue in Brazil territorialities}

\author{
Thiago Leandro Vieira Cavalcante ${ }^{2}$
}

Resumo: Dialogando com a teoria crítica descolonial latinoamericana, o texto apresenta o contexto brasileiro no que diz respeito à apropriação de terras de ocupação tradicional indígena por pessoas e instituições não indígenas, bem como as dificuldades encontradas pelos povos indígenas para reaverem essas terras, embora a Constituição Federal de 1988 tenha-lhes reconhecido esse direito originário. O trabalho sustenta que o Brasil está inserido em um contexto colonialista em que impera a validação de um único modelo de sociedade, que inclui um único modelo de territorialidade, diretamente ligado ao capitalismo neoliberal. Por fim, propõe que a aplicação da Interculturalidade Crítica pode ser um caminho de diálogo para a construção de uma sociedade em que várias formas de territorialidade possam coexistir.

Palavras-chave: interculturalidade; direitos indígenas; territorialidades; terras indígenas.

\begin{abstract}
Dialoging with the critical Latin American decolonial theory, the text presents the Brazilian context regarding the appropriation of lands of traditional indigenous occupation by non-indigenous people and institutions, as well as the difficulties encountered by indigenous people to recover these lands, although the Federal Constitution Recognized them. The paper argues that Brazil is inserted in a colonialist context in which the validation of a single model of society prevails, which includes a single model of territoriality,
\end{abstract}

\footnotetext{
${ }^{1}$ Este trabalho foi apresentado em formato de conferência no $1^{\circ}$ Coloquio Internacional Estudios de Género, Interculturalidad y Subjetividades, realizado nos dias 4-5 de maio de 2016 no Instituto de Investigaciones Sociales da Universidad Nacional Autónoma de México (UNAM).

${ }^{2}$ Universidade Federal da Grande Dourados (UFGD), Dourados, Mato Grosso do Sul, Brasil.
}

\section{Sobre o autor:}

Doutor em História pela Unesp/ Assis. Docente dos cursos de graduação e pós-graduação em História da UFGD. E-mail: thiago_cavalcante@hotmail.com 
directly linked to neoliberal capitalism. Finally, it proposes that the application of a critical interculturality can be a way for the dialogue that allows the construction of a society in which various forms of territoriality can coexist.

Key words: interculturality; indigenous rights; territorialities; indigenous lands.

\section{INTRODUÇÃO}

O Brasil tem um território de dimensões continentais, são mais de 8 milhões de $\mathrm{km}^{2}$. Nesse território, está abrigada uma enorme diversidade sociocultural. Há inúmeras diferenças, mesmo entre os cidadãos que não se reconhecem como membros de povos tradicionais e habitam as mais diversas regiões do Brasil. É evidente que não existe uniformidade cultural entre populações de estados do Norte e do Sul, por exemplo, às vezes, nem mesmo no interior de um estado tal uniformidade pode ser verificada.

Para além dessa diversidade (a dos não tradicionais), é preciso destacar a diversidade verificada com a presença das inúmeras comunidades tradicionais, tais como os povos indígenas, os quilombolas, os ribeirinhos, os povos da floresta e tantos outros que certamente formam um mosaico inacessível em sua integralidade até mesmo para os pesquisadores. No caso dos indígenas, que aqui terão maior destaque, no censo realizado em 2010 foram contabilizados 817,9 mil indígenas autodeclarados, divididos entre 305 etnias diferentes (IBGE, 2010); no geral representam cerca de $0,4 \%$ da população nacional, entretanto fazem com que o Brasil tenha uma das maiores e mais ricas diversidades socioculturais do planeta.

Historicamente, no entanto, o Brasil só reconheceu essa diversidade como algo positivo e que deve ser preservado na sua Constituição Federal de 1988. Por meio dela, oficialmente, o Estado abandonou a política assimilacionista e reconheceu o direito originário dos povos indígenas sobre suas terras de ocupação tradicional. Entretanto, na prática, o que se vê é que os ideais assimilacionistas continuam muito vivos no discurso e nas práticas estatais e, sobretudo, nos discursos produzidos pelas elites agrárias e econômicas do país.

Diante disso, em diálogo com alguns pensadores latinoamericanos (QUIJANO, 2005; WALSH, 2007; CASANOVA, 2006), caracterizei o Brasil como um Estado, que se pretende nacional, colonialista (CAVALCANTE, 2013). Esse colonialismo interno se dá em várias esferas; mas, nesse texto, darei maior destaque para a questão territorial. Buscarei aproximar as discussões sobre a interculturalidade à demanda concreta mais sensível e conflituosa na relação entre os povos indígenas e a sociedade não indígena brasileira que é 
a disputa que se trava pela posse de terras de ocupação tradicional indígena, que em grande parte se encontram ainda na posse de não indígenas.

De fato, há no Brasil uma disputa entre territorialidades, e não apenas uma disputa patrimonial. De um lado, os mais diversos povos indígenas, cada um com suas territorialidades específicas. De outro, uma concepção capitalista colonial de apropriação da terra que a vê ora como mercadoria e, quando muito, como meio de produção.

Até agora, o capital colonial hegemônico tem tido força para impor sua visão num projeto homogeneizador em curso no Brasil desde antes da sua independência. Esta perspectiva, hoje fortemente representada pelo neoliberalismo, impõe a todos uma visão eurocêntrica segundo a qual há apenas uma forma legítima de uso da terra, o discurso busca cristalizar na população a inexistência de modelos alternativos. Conforme Clavero (1994, p. 22-23 apud LANDER, 2005, p. 10):

[...] se não há cultivo ou colheita, nem a ocupação efetiva serve para gerar direitos; outros usos não valem, essa parte da terra, esse continente da América, ainda que povoado, pode ser considerado desocupado, à disposição do primeiro colono que chegue e se estabeleça. O indígena que não se atenha a esses conceitos, a tal cultura, não tem nenhum direito.

Eis aqui a linha de chegada do discurso proprietário, ponto de partida da concepção constitucional. E não é desde logo uma mera ocorrência de um pensador isolado. Estamos diante de uma manifestação realmente paradigmática de toda uma cultura, talvez ainda da nossa.

Para essa perspectiva constitucional, para esta nova mentalidade, os indígenas não reúnem as condições para terem direito algum, nem privado nem público. The Wealth of Nations de Adam Smith, sua riqueza das nações não menos paradigmática, contém e difunde a conclusão: 'The native tribes of North America' não têm por seu particular 'state of society', por um lado julgado primitivo, 'neither sovereign nor commonwealth', nem sobreano, nem república, tampouco algum direito político.

Cabe destacar o que estou chamando aqui de territorialidade. A partir de diálogos com a Geografia e a Antropologia (HAESBAERT, 2010; LITTLE, 2002), entendo que a territorialidade é a relação específica construída por cada grupo humano para apropriação e significação de um determinado espaço geográfico, tornando-o assim um território. Tal apropriação envolve uma construção baseada em aspectos sociais, simbólicos, culturais, econômicos e políticos. Ou seja, a territorialidade de cada grupo humano define a relação que esse grupo estabelece com o seu território. Logo, conclui-se que tal qual a grande diversidade sociocultural, podemos falar numa diversidade de territorialidades, visto que grupos distintos se relacionam diferentemente com seus territórios. 
Sendo assim, a proposta que apresento aqui é a de que, tal qual a ferramenta da interculturalidade é utilizada na tentativa de produção de relações culturais e epistêmicas horizontais, a interculturalidade também possa ser utilizada como ferramenta para um diálogo que possibilite uma relação horizontal quando o assunto em discussão for a disputa entre os povos indígenas e, sobretudo, o agronegócio por terras de ocupação tradicional indígena.

Logicamente, há que se evocar a chamada interculturalidade crítica, aquela proposta por Fidel Tubino e por Catherine Walsh e que extrapola o simples reconhecimento das diferenças, mas questiona as causas da assimetria cultural e social buscando suprimi-las. Nega-se, portanto, a perspectiva ocidentalizante da modernidade. Tal interculturalidade crítica, nos termos propostos por Catherine Walsh, deve ser acompanhada de uma perspectiva descolonial; é, portanto, radicalmente diversa do multiculturalismo liberal (TUBINO, 2005; WALSH, 2007).

\section{A DIVERSIDADE E SUA NEGAÇÃO NO BRASIL}

Como já apresentado, no Brasil são identificados mais de 300 grupos étnicos indígenas, que falam aproximadamente 150 línguas distintas. É, sem dúvidas, uma das maiores diversidades socioculturais do planeta. Não há como saber com exatidão quantos eram os povos no momento da invasão europeia, todavia, estima-se que esse número fosse superior a 1.000 (INSTITUTO SOCIOAMBIENTAL [ISA], 2016a; IBGE, 2010).

Não há como negar que a atividade colonial, independente do agente causador, foi a principal responsável pela drástica redução dessa população. Diferentemente, portanto, de outros países latinoamericanos, no Brasil os indígenas formam uma minoria populacional, o que torna o diálogo da sociedade nacional para com eles ainda mais difícil.

Oficialmente, em 7 de setembro de 1822, o Brasil se tornou independente de Portugal. À primeira vista isso poderia ser visto como o final do colonialismo, entretanto não foi isso que aconteceu, pois o colonialismo interno e as colonialidades do poder e do saber persistem atuando.

Não se pode dizer que a independência do Brasil tenha sido um processo revolucionário. De fato, foi um acordo entre as elites do qual participaram as oligarquias agrárias, militares, maçons e uma parte da nobreza portuguesa, entre eles o príncipe regente do Brasil e herdeiro do trono português, que em seguida seria o primeiro monarca do Brasil, D. Pedro I³ (FAUSTO, 1995; SPOSITO, 2012).

\footnotetext{
${ }^{3}$ Em 1831 D. Pedro I abdicou ao trono do Brasil em favor de seu filho D. Pedro II. Tal atitude foi tomada para que Pedro I pudesse assumir o trono português. Diante da minoridade de D. Pedro II, entre 1831 e 1840, o Brasil foi governado por regentes.
} 
O capitalismo desenvolvido no Brasil foi e continua sendo extremamente eurocentrado. Inicialmente, baseado numa divisão racial do trabalho sendo que aos índios cabia a servidão ou a exclusão, aos negros, a escravidão e, apenas e tão somente aos brancos, o trabalho assalariado. No Brasil contemporâneo, embora oficialmente a escravidão e a servidão estejam proibidas, persiste claramente essa divisão racial do trabalho, sendo que os negros e indígenas raramente ocupam alguma posição de destaque no mundo do trabalho capitalista. Tais características levam a propor, seguindo o pensamento de Anibal Quijano (2005), que o Brasil se tornou um Estado independente, mas com uma sociedade colonial.

Na prática, os colonizadores externos, que, entretanto, sempre mantiveram sua influência independente de dominação política, foram substituídos por membros de uma elite local que se encarregou da implantação de um verdadeiro colonialismo interno, aqui pensado a partir da definição de Casanova (2006), que segue operante até a atualidade.

O Brasil viveu uma independência chefiada por liberais conservadores que culminou na instituição de um Estado politicamente independente chefiado pelo príncipe herdeiro da coroa portuguesa. Desde seu princípio, indígenas, negros (escravos ou livres) e os pobres em geral, ou foram totalmente excluídos da cidadania, ou tiveram acesso a ela de forma totalmente limitada.

Fernanda Sposito (2012, p. 24-25) aponta, por exemplo, que durante as discussões travadas na Assembleia Nacional Constituinte em 1823, houve intensas discussões sobre quem seriam os membros do pacto político que seria selado com a constituição de uma nova nação. As discussões levaram a uma cisão excludente. Haveria aqueles que seriam considerados brasileiros e cidadãos e aqueles que, embora brasileiros, não poderiam receber o status de cidadãos, ou seja, não comporiam a sociedade civil brasileira.

O discurso do deputado fluminense Manoel José de Souza França é emblemático nesse sentido.

Nós não podemos deixar de fazer esta diferença ou divisão de brazileiros e cidadãos brazileiros. Segundo a qualidade de nossa população, os filhos dos negros, crioulos e captivos, são nascidos no territorio do Brazil, mas todavia não são cidadãos brazileiros. Devemos fazer essa differença: brazileiro é o que nasce no Brazil, e cidadão brazileiro é aquelle que tem direitos civicos. Os indios que vivem nos bosques não são brazileiros, enquanto não abraçam a nossa civilização. Convém por conseqüência fazer esta diferença por ser heretogenea a nossa população ${ }^{4}$. (FRANÇA apud SPOSITO, 2012, p. 24).

\footnotetext{
${ }^{4}$ Fala do deputado França em sessão de 23 de setembro de 1823. APB. Assembléia Constituinte, 1823. T. 5․ Rio de Janeiro: Typographia de H. J. Pinto, 1880, p. 211. Essa discussão inicia-se em 23 de setembro a partir da emenda do deputado Vergueiro e estende-se até a sessão de 30 de setembro, p. 211-59.
} 
A cidadania era reservada a poucos. Escravos e ex-escravos, embora pudessem ser considerados brasileiros em face do seu nascimento no território do novo Estado, não poderiam ser considerados cidadãos.

A situação dos indígenas era ainda pior, subumana, no mínimo, pois não eram nem cidadãos nem brasileiros. Só poderiam ser considerados brasileiros, após passarem pelo processo de integração, leia-se assimilação, à dita sociedade nacional (SPOSITO, 2012).

É relevante, portanto, destacar que a sociedade brasileira desde seu princípio foi constituída politicamente por valores liberais e que perpetuaram a colonialidade excludente e homogeneizadora, que não respeita as diferenças culturais, incluindo aí as diferenças de territorialidades e a Constituição Federal de 1988, instrumento jurídico avançado em termos de direitos coletivos, que não foi suficiente para quebrar esse paradigma.

Certamente, como lembrado por Quijano (2005), o Brasil não se constituiu como uma nação, mas tão somente como um Estado independente e colonial. Isso porque não havia unidade de interesses entre a maioria dos habitantes daquele território. Entretanto isso foi motivo de preocupações por parte das elites dominantes que temiam a desintegração do Estado.

Percebendo a fragilidade da "nação brasileira", que de fato não existia enquanto tal, no segundo reinado (1840-1889), sob o comando de D. Pedro II, as elites nacionais brasileiras buscaram meios para a construção de uma identidade nacional que possibilitasse a consolidação do jovem Estado nacional. Nesse ponto, as discussões travadas no Instituto Histórico e Geográfico Brasileiro (IHGB) foram de suma importância.

Em tal contexto, o índio passou a ser visto como problema nacional (não muito diferente da atualidade), diversos intelectuais do século XIX apresentaram suas propostas para a solução dessa questão. A intensa ocupação do território nacional pelas populações indígenas foi a principal motivadora de tais preocupações. Primeiramente havia a preocupação com delimitação das fronteiras nacionais. Também era forte a questão relacionada à posse de terras. Diante de tal contexto, o Estado imperial implantou uma série de medidas indigenistas específicas que visavam civilizar e integrar os índios à sociedade brasileira. Optou-se pela construção de uma identidade nacional branca e europeia, na qual não havia espaço para os índios, a eles cabia a integração. A construção da pretensa identidade nacional foi acompanhada da anulação da diversidade étnica (MOTA, 1998; 2006).

A política indigenista do império tinha como meta a assimilação dos povos indígenas. A incorporação e expropriação de suas terras ocupavam 
lugar importante na pauta do Estado. A política indigenista da época não se pautou nas necessidades dos povos indígenas, como se tentava fazer pensar, mas, sim, nas necessidades da sociedade envolvente. Tal indigenismo favorecia a expansão das grandes propriedades agrárias e a projetos específicos de colonização (MOTA, 1998, p. 150-152).

É factível afirmar que, desde o império até a proclamação da Constituição Federal de 1988, a política indigenista brasileira visava à assimilação dos povos indígenas e à eliminação da diversidade étnica, cultural, linguística e de territorialidades. Após 1988, embora formalmente o Estado tenha reconhecido o direito à diferença e assumido a responsabilidade por sua proteção, o que se vê ainda é a predominância de práticas assimilacionistas que não reconhecem o direito à diferença, principalmente quando esta diferença tem a ver com territorialidades e direitos territoriais.

\section{A LEI DE TERRAS E A CONCENTRAÇÃO DE TERRAS ENTRE AS OLIGARQUIAS HEGEMÔNICAS}

Outro aspecto importante da história brasileira está ligado à forte concentração de terras nas mãos de poucos cidadãos e hoje, sobretudo, de corporações. Antes da abolição da escravidão (1888), em 18 de setembro de 1950 foi editada Lei n. 601, conhecida como "Lei de Terras". Ela proibiu a aquisição de terras devolutas por outros meios que não fossem a compra. Na prática, a lei limitou o acesso a terra somente àqueles que pudesse pagar por ela. A partir de então, qualquer posse constituída por meios que não fossem a compra, não poderia ser legitimada como propriedade. Com isso, especialmente os escravos que viriam a ser "libertos" alguns anos depois, não poderiam assumir uma forma de vida autônoma em relação aos seus antigos senhores.

A partir da vigência da Lei de Terras, milhares de hectares foram entregues à elite agrária nacional, incluindo aí boa parte das terras de ocupação tradicional indígena. Inequivocadamente é possível afirmar que a Lei de Terras de 1950 favoreceu a concentração de terras no Brasil, consolidando o latifúndio monocultor como tipo de propriedade predominante e deu legitimidade a muitos processos de esbulho territorial contra indígenas em diversas regiões do país (PACHECO, 2004; CAVALCANTE, 2013).

Em 2006, o Instituto Brasileiro de Geografia e Estatística (IBGE) apontou a enorme concentração de terras no país.

O Censo Agropecuário 2006 revelou que a concentração na distribuição de terras permaneceu praticamente inalterada nos últimos vinte anos, 
embora tenha diminuído em 2.360 municípios. Nos Censos Agropecuários de 1985, 1995 e 2006, os estabelecimentos com mais de 1.000 hectares ocupavam $43 \%$ da área total de estabelecimentos agropecuários no país, enquanto aqueles com menos 10 hectares ocupavam, apenas, 2,7\% da área total. Focalizando-se o número total de estabelecimentos, cerca de $47 \%$ tinham menos de 10 hectares, enquanto aqueles com mais de 1.000 hectares representam em torno de $1 \%$ do total, nos censos analisados. (IBGE, 2009).

Ou seja, 1\% do total das propriedades rurais (aquelas com mais 1000 hectares) ocupava $43 \%$ da área dos estabelecimentos rurais; enquanto os $47 \%$ compostos por pequenas propriedades (aquelas com menos de 10 hectares) ocupavam somente $2,7 \%$ da área composta por estabelecimentos rurais. Já a outra metade da área ocupada por estabelecimentos rurais era composta por propriedades médias que variam entre 11 e 999 hectares. Em termos gerais, não é preciso um esforço muito grande para concluir que a concentração de terras no Brasil ainda é assustadoramente desigual perpetuando um processo que teve início ainda antes da independência e que foi consolidado a partir de 1850.

\section{A IMPOSIÇÃO DE UMA TERRITORIALIDADE LEGITIMADA PELO CAPITAL}

A diversidade de territorialidades no Brasil é tão ou até mais negada do que a diversidade cultural e linguística, estas encontram algum respaldo teórico no multiculturalismo liberal. Há, no entanto, um discurso que legitima apenas uma forma de ocupação e uso da terra, qual seja: o discurso da "produção", nesse campo não há margem para a atuação do multiculturalismo, pois esse não avança sobre a necessidade de mudanças na estrutura das sociedades coloniais.

O discurso hegemônico em todo o Brasil é o discurso da "produção". Agropecuaristas não são mais agropecuaristas, são "produtores rurais". Tal discurso é proferido e defendido pela grande imprensa, por governantes e por entidades de classe. O grande problema é a carga de subjetividade que esse discurso carrega, pois opõe aqueles que são considerados "produtores" aos que supostamente nada produzem (indígenas, quilombolas, membros de movimentos sociais que reivindicam a reforma agrária etc.) e, por tanto, não deveriam ter acesso a terra. Há por trás disso uma questão maior que é a legitimação de uma única territorialidade, forma essa legitimada pelo capital colonialista agroexportador. Essa territorialidade é aquela que se apropria da terra apenas enquanto meio de produção para uma modalidade 
bem específica de produção que é as das commodities para o atendimento do mercado internacional. Como já está muito claro, o agronegócio não produz os alimentos consumidos pelos brasileiros. Estes vêm da agricultura familiar ou camponesa. Tal discurso, entretanto, não ataca as terras apropriadas com finalidades especulatórias, modalidade também comum e muito utilizada pelo capital financeiro. Percebe-se, portanto, ainda mais a permanência de ideais colonialistas nas relações entre a elite nacional e os povos indígenas e outras comunidades tradicionais, bem como com integrantes de movimentos sociais.

O que os autodenominados "produtores rurais" abominam é a possibilidade de convivência com outras formas de territorialidades, como as dos povos indígenas, uma vez que elas não atendem à lógica do capitalismo global. Diante disso, são combatidas e devem ser extirpadas obedecendo à lógica excludente da colonialidade do poder e do saber, que também são fortemente visualizadas no Brasil como uma expressão de colonialismo interno, quando as classes dominantes nacionais, sempre em associação com o capital internacional continuam se relacionando com as populações locais subalternizadas a partir da lógica colonial de exploração (CAVALCANTE, 2013).

\section{O CASO DOS KAIOWA E GUARANI DE MATO GROSSO DO SUL}

Principalmente desde os anos 1990, a história dos Guarani e Kaiowa tem sido analisada por vários autores, tais como Antonio Brand (1993; 1997; 2004), Jorge Eremites de Oliveira e Levi Marques Pereira (2009), entre outros, que produziram diversos trabalhos que abordam a questão desde o ponto de vista mais delimitado até a visões mais gerais. Em 2013, defendi uma tese, recentemente publicada (CAVALCANTE, 2016), na qual apresentei uma síntese do processo colonial imposto aos Guarani e Kaiowa em Mato Grosso do Sul. Naquele trabalho, dialoguei com uma extensa bibliografia, a qual não apresentarei em detalhes por fugir dos propósitos desse trabalho.

Embora essa reflexão se refira a uma proposta de aplicação de interculturalidade crítica num âmbito mais abrangente da discussão da diversidade de territorialidades no Brasil, utilizarei o caso dos Kaiowa e Guarani que vivem do atual estado de Mato Grosso do Sul, localizado na região Centro-Oeste do Brasil, como um exemplo emblemático. Entretanto é certo que outros povos de todo o país vivem histórias semelhantes.

Os Kaiowa e os Guarani são dois grupos indígenas bastante numerosos, juntos somam cerca de 50.000 mil pessoas que vivem na região sul de Mato Grosso do Sul, estado que concentra a segunda maior população indígena do 
Brasil. São cultural e linguísticamente muito próximos, entretanto distinguem-se etnicamente.

Durante o período colonial, principalmente no século XVII, tiveram alguns contatos com os colonizadores espanhóis e paulistas, principalmente missionários jesuítas e bandeirantes paulistas que vinham até a região na tentativa de apresar indígenas para servirem como mão de obra escrava na Capitania de São Vicente.

Depois de muitos ataques enfrentados pelas Reduções Jesuítico-Guaranis, as reduções foram abandonadas, e os indígenas que permaneceram na região não sofreram grandes importunações até meados do século XIX.

Todavia, entre 1864 e 1870, o território tradicional kaiowa e guarani foi palco de um grande conflito militar, a chamada "Guerra do Paraguai" ou a "Guerra da Tríplice Aliança". Nesse conflito, o Paraguai disputou a soberania de territórios com o Brasil, a Argentina e o Uruguai. Finda a guerra, com o Paraguai derrotado, foram confirmadas as fronteiras reivindicadas pelo Brasil no período anterior à guerra.

Entretanto o Estado Brasileiro precisava garantir a soberania na região que era percebida como espaço vazio, embora na realidade fosse habitada por milhares de indígenas, mas, como visto, não eram considerados efetivamente brasileiros, tampouco detentores de efetivos direitos territoriais.

Inicialmente, o governo brasileiro concedeu grandes extensões de terras em arrendamento para a Companhia Mate Laranjeira que, por décadas, explorou a extração de erva mate na região ${ }^{5}$. Logo em seguida, inúmeros projetos federais e também estaduais de colonização passaram a conceder para não indígenas títulos de propriedade sobre terras de ocupação tradicional indígena.

Por meio do Decreto n. 8.072 de 20 de junho de 1910, o governo brasileiro criou o Serviço de Proteção ao Índio e Localização de Trabalhadores Nacionais (SPILTN), que, em 1918, se tornou apenas Serviço de Proteção ao Índio (SPI). A atuação desse órgão em Mato Grosso do Sul foi emblemática na representação da ambiguidade do Estado Brasileiro. A despeito das normas constitucionais e dos preceitos previstos no decreto de criação do SPI - segundo os quais o órgão deveria defender os direitos indígenas, inclusive os territoriais - este órgão, assim como sua sucessora, a Fundação Nacional do Índio (FUNAI), de fato foi concebido para atuar no sentido de evitar que os indígenas fossem

\footnotetext{
${ }^{5}$ Em 1895, ápice da Mate Larangeira, a Companhia detinha a concessão de 5 milhões de hectares de terras. Ver mais em: Ver mais sobre a Matte Larangeira em: Ferreira (2007), Brand (1993), Queiroz (2010; 2012).
} 
um entrave ao chamado "progresso". Ou seja, o órgão indigenista oficial foi e é um mediador entre os interesses do capital e do Estado e os interesses dos povos indígenas, os quais, em geral são preteridos. No passado, esses direitos foram abertamente negados, hoje continuam sendo negados, mas de forma encoberta por uma cortina de fumaça representada pelo discurso estatal que supostamente respeita a diversidade sociocultural.

No sul de Mato Grosso do Sul, entre 1915 e 1928, o SPI criou oito pequenas reservas indígenas destinadas à população guarani e kaiowa. Essas reservas cumpriram dois principais objetivos: $1^{\circ}$ ) o de liberar terras indígenas para a colonização; $2^{\circ}$ ) o de pôr em prática a política indigenista de orientação assimilacionista, oficialmente em voga até 1988.

Nesse entremeio, até a década de 1990, com a aplicação de várias estratégias pelos contrários aos indígenas, os Guarani e Kaiowa, paulatinamente, tiveram o seu território subtraído e foram amontoados nas pequenas reservas indígenas (CAVALCANTE, 2013).

Atualmente, ocupam pouco mais de 30 mil hectares. Há ainda, aproximadamente, 127 mil hectares que, embora reconhecidos pelo Estado enquanto terras indígenas, estão nas mãos de ocupantes não indígenas, em sua maioria grandes proprietários de terras ${ }^{6}$.

Enquanto isso, os indígenas amargam graves problemas sociais e são vítimas contumazes de violências. A desnutrição infantil, o alto índice de suicídios e de assassinatos chama a atenção de todo o mundo, mas não são capazes de sensibilizar as classes dominantes brasileiras. Segundo dados do Conselho Indigenista Missionário (órgão ligado à Igreja Católica), Mato Grosso do Sul concentra o maior número de assassinatos de indígenas desde 2003. Em 2014, foram 41 casos (CONSELHO INDIGENISTA MISSIONÁRIO [CIMI], 2015, p. 76).

No ano de 2007, durante o segundo mandato do presidente Luiz Inácio Lula da Silva, a FUNAI assinou um Compromisso junto ao Ministério Público Federal, por meio do qual, reconheceu que não estava cumprindo com as responsabilidades de execução da demarcação e proteção de terras indígenas estabelecidas pela Constituição de 1988 para o governo federal. Por meio desse acordo, em troca do não ajuizamento de ação judicial, o órgão federal se comprometeu a realizar estudos para a demarcação de pelo menos 39 tekoha

\footnotetext{
${ }^{6}$ Essas terras, já reconhecidas, encontram-se em uma das diferentes fases previstas no Decreto 1.775/1996 que regulamenta o processo de demarcação e regularização fundiária de terras indígenas. Além disso, todos os atos do governo no sentido de avançar na regularização de terras indígenas são questionados na Justiça Federal, provocando atrasos ainda maiores dos que o já verificáveis no processo administrativo.
} 
(áreas de ocupação tradicional kaiowa e guarani). Entretanto, até o momento, esses estudos tiveram pouquíssima efetividade e foram preteridos em nome de acordos políticos celebrados com representantes do poder regional. Sobretudo durante os governos de Dilma Rousseff, esses estudos deixaram de avançar, e a regularização de terras indígenas em Mato Grosso do Sul entrou em estado de quase estagnação (CAVALCANTE, 2013).

\section{O RURALISMO E SUA SEDE HOMOGENEIZANTE}

Após a assinatura do já mencionado Compromisso de Ajustamento de Conduta pela FUNAI, em 2008 e nos anos seguintes, assistiu-se a uma contraofensiva do setor do agronegócio que, com sua "ideologia ruralista"7, disseminou uma intensa campanha de formação da opinião pública contrária à efetivação dos direitos territoriais indígenas em Mato Grosso do Sul e no Brasil como um todo.

A bancada ruralista (deputados e senadores que têm suas campanhas eleitorais financiadas pelo agronegócio para defenderem os seus interesses) é composta por mais de um terço dos parlamentares do Congresso Nacional. Estes, aliados com outros setores liberais e conservadores, formam a hegemonia política no parlamento e são capazes de influenciar, de forma decisiva, as ações do governo brasileiro, especialmente porque este, sem maioria parlamentar, depende de alianças espúrias para governar e para se manter no poder pela via das eleições quadrienais.

De fato, os governos Lula e Dilma produziram avanços sociais importantes no país, mas insignificantes no campo das demarcações de terras indígenas, para não falar de reforma agrária. Por exemplo, os números mostram que Dilma foi a presidente que menos homologou demarcações de terras indígenas desde o final da ditadura civil-militar que durou de 1986-1964 (ISA, 2016b).

Além de retardar ou paralisar os trabalhos técnicos realizados pela Fundação Nacional do Índio, os parlamentares investem na modificação da legislação e da própria Constituição Federal. A Proposta de Emenda Constitucional n. 215/2000, que pretende transferir a prerrogativa da homologação da demarcação de terras indígenas do presidente da república para o Congresso Nacional é vista como a maior das ameaças vindas de iniciativas legislativas atualmente.

Para além da influência que o ruralismo tem no campo político, há que se dar destaque para o fato de que ele não se constitui simplesmente como um

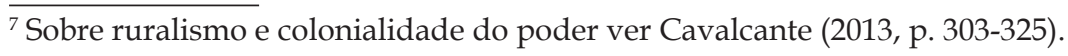


corpo de pessoas unidas por interesses corporativos, mais do que isso, trata-se de uma ideologia capaz que reunir defensores de seus ideais, especialmente um suposto caráter sagrado da propriedade privada, até mesmo entre outros grupos sociais subalternizados, como trabalhadores urbanos, trabalhadores rurais e pequenos comerciantes. Tais grupos são falsamente convencidos de que o único modelo possível de sociedade organizada é o neoliberal, que, nesse nível, conforme Edgardo Lander, não deve ser compreendido e combatido apenas como uma teoria econômica, mas sim

[...] como um modelo civilizatório, isto é, como uma extraordinária síntese dos pressupostos e dos valores básicos da sociedade liberal moderna no que diz respeito ao ser humano, à natureza, à história, ao progresso, ao conhecimento e a boa vida. As alternativas às propostas neoliberais e ao modelo de vida que representam não podem ser buscados em outros modelos ou teorias no campo da economia, visto que a própria economia como disciplina científica assume, em sua essência, a visão de mundo liberal. (LANDER, 2005, p. 7).

Além disso, o Poder Judiciário brasileiro contribui decisivamente para a não efetivação dos direitos territoriais indígenas. Tal contribuição se dá tanto pela via de decisões judiciais que vão claramente contra ao que está previsto na Constituição Federal de 1988, quanto com a morosidade na tramitação de processos que tratam de terras indígenas.

Por fim, nesse ponto, cabe destacar que a violência simbólica empregada pelo ruralismo está relacionada à necessidade premente de defesa do discurso agroexportador no Brasil. Tal movimento está relacionado a um fenômeno de reorganização do capital em nível mundial. Diante desse processo, o Brasil atual sofre um processo de desindustrialização e passa a dar ainda mais importância a seu papel de produtor e exportador de produtos primários e consumidor de produtos industrializados, sendo assim, a manutenção da concentração da propriedade das terras é fundamental para que os objetivos do grande capital estrangeiro sejam atingidos. Ou seja, continuam operando valores coloniais, mesmo após quase dois séculos de independência política.

\section{DA INTERCULTURALIDADE FUNCIONAL À INTERCULTURALIDADE CRÍTICA DESCOLONIZADORA}

Como já visto, a Constituição Federal brasileira de 1988 reconheceu o caráter multicultural do Brasil, bem como o direito originário dos povos indígenas sobre suas terras de ocupação tradicional. Em decorrência disso, vivenciam-se, desde os anos 1990, diversas iniciativas e experiências de educação escolar indígena que se pretendem diferenciadas. Isso se dá também 
num contexto de formação de professores indígenas com base na ideia da interculturalidade.

Embora não seja o objetivo deste trabalho, há que se registrar que, embora haja exceções muito positivas, ainda predominam as ações pautadas pela ideia de interculturalidade funcional, que é compatível como o modelo neoliberal, pois, embora promova o diálogo e a tolerância entre os diferentes, não toca nas causas das assimetrias vigentes (TUBINO, 2005).

Todavia, quando a questão se refere às terras indígenas, não há sequer possibilidade de destacarmos a existência de um diálogo funcional. Simplesmente a sociedade não indígena não admite outra forma de territorialidade que não seja a voltada para a produção de commodities, ou seja, para a geração de lucros no âmbito do sistema capitalista neoliberal.

Nesse ponto, é necessário que se promova um diálogo intercultural capaz de demonstrar para as pessoas, sobretudo para aquelas que não são diretamente afetadas pelo sucesso dos pleitos indígenas (que é a maioria da população), que é necessário que se reconheça e respeite a existência de diversas formas de se relacionar com o território. Ou seja, assim como já está aceita pela maioria da população a ideia de que existe uma diversidade cultural e que está merece ser respeitada (embora na prática nem sempre isso seja verdadeiramente aceito), é preciso que as pessoas compreendam que há diversas formas de territorialidades e que sua coexistência jamais inviabilizará o modo de vida dos não índios.

Evidentemente que esse reconhecimento não é suficiente, é um passo necessário, para que se avance para o modelo pretendido pela interculturalidade crítica. Assim, será possível que de fato os povos indígenas recebam ao menos uma parte de suas terras de ocupação tradicional e, assim, consigam ter uma vida pouco mais semelhante àquela que compreendem como modelo ideal.

A interculturalidade crítica, proposta por Tubino e Walsh, não pode ser descolada de uma atitude descolonial, ou seja, o diálogo deve ser posto em prática a partir de uma simetria de relações, nesse caso, entre indígenas e não indígenas. Não se pode pensar numa interculturalidade efetiva se os indígenas não tiverem sua cidadania de fato reconhecida pelo Estado brasileiro.

O conceito de interculturalidade não deve, como algumas vezes ocorre, ser utilizado como um eufemismo empregado pelo Estado para ocultar a existência de povos subalternizados pelo colonialismo interno.

[...] La interculturalidad no está entendida como un simple nuevo concepto o término para referir al contacto y al conflito entre el Occidente y 
otras civilizaciones (como algunos lo entienden a menudo). Tampouco sugiere una nueva política o lo que Dussel (2001) llama una 'antipolíti$\mathrm{ca}^{\prime \prime}$ (p. 11) que, originada en 'una práctica emancipatoria, deriva de una responsabilidad hacia al Otro'.

Representa, en cambio, una configuración conceptual, una ruptura epistémica que tiene como base el pasado y el presente, vividos como realidades de dominación, explotación y marginalización, que son simultáneamente constitutivas, como consecuencia de lo que Mignolo ha llamado modernidad/colonialidad. Una configuración conceptual que, al mismo tiempo que construye una respuesta social, política, ética y epistémica para esas realidades que ocurrieron y ocurren, lo hace desde un lugar de enunciación indígena [...]. (WALSH, 2007, p. 50).

A interculturalidade deve ser compreendida como um projeto político anti-hegemônico que deve ser proposto e assumido em primeiro lugar pelos próprios indígenas e, sobretudo, a partir de práticas educacionais libertadoras pelas demais camadas subalternizadas da sociedade brasileira.

Finalizando, entendo que a via da interculturalidade crítica é um caminho para a quebra do modelo de pensamento único responsável por este universalismo excludente (LANDER, 2005, p. 10) que não reconhece aos indígenas o direito juridicamente já reconhecido às suas terras de ocupação tradicional.

\section{REFERÊNCIAS}

BRAND, Antonio Jacó. Os complexos caminhos da luta pela terra entre os Kaiowá e Guarani no MS. Tellus, Campo Grande, v. 6, n. 1, p. 137-150, 2004.

. O impacto da perda da terra sobre a tradição Kaiowa/Guarani: os difíceis caminhos da palavra. 1997. Tese (Doutorado em História) - Pontifícia Universidade Católica do Rio Grande do Sul, Porto Alegre, RS, 1997.

. O confinamento e o seu impacto sobre os Pai-Kaiowá. 1993. Dissertação (Mestrado em História) - Pontifícia Universidade Católica do Rio Grande do Sul, Porto Alegre, RS, 1993.

CASANOVA, Pablo González. Colonialismo Interno (uma redefinição). In: BORON, A. A.; AMADO, J.; GONZÁLEZ (Org.). A teoria marxista hoje: problemas e perspectivas. Buenos Aires: CLACSO, 2006. p. 395-420.

CAVALCANTE, Thiago Leandro Vieira Cavalcante. Colonialismo, território e territorialidade. A luta pela terra dos Guarani e Kaiowa de Mato Grosso do Sul. Jundiaí, SP: Paco Editorial, 2016.

Colonialismo, território e territorialidade. A luta pela terra dos Guarani e Kaiowa de Mato Grosso do Sul. 2013. Tese (Doutorado em História) - Faculdade de Ciências e Letras - Universidade Estadual Paulista, Assis, SP, 2013. 
CONSELHO INDIGENISTA MISSIONÁRIO (CIMI). Relatório. Violência contra os povos indígenas no Brasil. Dados de 2015. Brasília: CIMI, 2015.

EREMITES DE OLIVEIRA, Jorge; PEREIRA, Levi. Nande Ru Marangatu. Laudo antropológico e histórico sobre uma terra kaiowa na fronteira do Brasil com o Paraguai, município de Antônio João, Mato Grosso do Sul. Dourados, MS: Editora UFGD, 2009.

FAUSTO, Boris. História do Brasil. 2. ed. São Paulo: Editora da USP, 1995.

FERREIRA, Eva Maria Luiz. A participação dos indios kaiowá e guarani como trabalhadores nos ervais da Companhia Matte Larangeira (1902-1952). 2007. Dissertação (Mestrado em História) - Universidade Federal da Grande Dourados, Dourados, MS, 2007.

HAESBAERT, Rogério. O mito da desterritorialização: do "fim dos territórios" à multiterritorialidade. 5. ed. Rio de Janeiro: Bertrand Brasil, 2010.

INSTITUTO BRASILEIRO DE GEOGRAFIA E ESTATÍSTICA (IBGE). Censo demográfico 2010. Características Gerais dos Indígenas. Resultados do Universo. Rio de Janeiro: IBGE, 2010.

. Censo Agro 2006: IBGE revela retrato do Brasil agrário. 30 set. 2009. Disponível em: <http:/ / saladeimprensa.ibge.gov.br/noticias?view=noticia\&id=1\&busca=1\&id noticia $=1464>$. Acesso em: 3 abr. 2013.

INSTITUTO SOCIOAMBIENTAL (ISA). Introdução. 2016a. Disponível em: <https:/ / pib.socioambiental.org/pt/c/no-brasil-atual/linguas/introdução>. Acesso em: 23 fev. 2016.

. Demarcações nos últimos seis governos. Atualizada em 12 de maio de 2016b. Disponível em: <https://pib.socioambiental.org/pt/c/0/1/2/demarcacoes-nos-ultimos-governos>. Acesso em: 23 nov. 2016b.

LANDER, Edgardo. Ciências Sociais: saberes coloniais e eurocêntricos. In: LANDER, E. (Org.). A colonialidade do saber: eurocentrismo e ciências sociais. Perspectivas latino-americanas. Buenos Aires: CLACSO, 2005.

LITTLE, Paul E. Territórios sociais e povos tradicionais no Brasil: por uma antropologia da territorialidade. Série Antropologia, Brasília, n. 322, 2002.

MOTA, Lúcio Tadeu. A Revista do Instituto Histórico Geográfico Brasileiro (IHGB) e as populações indígenas no Brasil do II Reinado (1839-1889). Diálogos, Maringá, PR, v. 10, n. 1, p. 118-142, 2006.

. O IHGB e as propostas de integração das comunidades indígenas no Estado nacional. Diálogos, Maringá, PR, v. 2, n. 2, p. 149-175, 1998.

PACHECO, Rosely A. Stefanes. Mobilidades guarani Kaiowá e Nandeva e a (re) construção de territórios (1978-2003): novas perspectivas para o direito indígena. 2004. Dissertação (Mestrado em História) - Universidade Federal de Mato Grosso do Sul, Dourados, MS, 2004.

QUEIROZ, Paulo R. Cimó. A Companhia Matte Larangeira e seus fluxos mercantis (1891-1902). In: CONGRESO LATINOAMERICANO DE HISTORIA ECONÓMICA, 3. 
/JORNADAS DE HISTORIA ECONÓMICA, 23., 2012, Bariloche (Argentina). Anais... Buenos Aires (Argentina): Asociación Argentina de Historia Económica, 2012. p. 1-25.

A grande empresa conhecida como Matte Larangeira e a economia ervateira na bacia platina (1882-1949): notas preliminares. In: PRIMEIRO ENCONTRO DE PÓS-DOUTORES DO PPGH/UFF, 2010, Niterói. Anais... Niterói, RJ: UFF, 2010. p. 1-19

QUIJANO, Aníbal. Colonialidade do poder, eurocentrismo e América Latina. In. LANDER, E. (Org.). A colonialidade do saber: eurocentrismo e ciências sociais. Perspectivas latino-americanas. Buenos Aires: CLACSO, 2005.

SPOSITO, Fernanda. Nem cidadãos, nem brasileiros. Indígenas na formação do Estado nacional brasileiro e conflitos na província de São Paulo (1822-1845). São Paulo: Alameda, 2012.

TUBINO, Fidel. Del interculturalismo funcional al interculturalismo crítico. 2005. Disponível em: <http:/ / red.pucp.edu.pe/wp-content/uploads/biblioteca/inter_funcional. pdf>. Acesso em: 23 fev. 2015.

WALSH, Catherine. Interculturalidad y colonialidad del poder. Un pensamiento y posicionamiento "otro" desde la diferencia colonial. In: CASTRO-GÓMEZ, S.; GROSFOGUEL, R. (Ed.). El giro decolonial: reflexiones para una diversidad epistémica más allá del capitalismo global. Bogotá: Siglo del Hombre Editores; Universidad Central, Instituto de Estudios Sociales Contemporáneos y Pontificia Universidad Javeriana, Instituto Pensar, 2007.

Recebido em 27 de novembro de 2016 Aprovado para publicação em 28 de novembro de 2016 
